\title{
Sistem Informasi Inventaris Barang Pada Badan Pendapatan Daerah Provinsi Sumatera Selatan
}

\author{
Panji Hastomo ${ }^{1}$, Rusmala Santi ${ }^{2}$, Muhamad Kadafi ${ }^{3}$ \\ hastomo.p@gmail.com ${ }^{1}$,rusmalasanti_uin@radenfatah.ac.id ${ }^{2}$, kadafi_uin@radenfatah.ac.id ${ }^{3}$ \\ ${ }^{1}$ Prodi Sistem Informasi, Fakultas Sains dan Teknologi, UIN Raden Fatah Palembang \\ ${ }^{2}$ Prodi Sistem Informasi, Fakultas Sains dan Teknologi, UIN Raden Fatah Palembang \\ ${ }^{3}$ Prodi Sistem Informasi, Fakultas Sains dan Teknologi, UIN Raden Fatah Palembang
}

Diterima: 5 Juli 2017 | Direvisi: 28 Agustus 2017 | Disetujui: 22 September 2017

(c) 2017 Program Studi Sistem Informasi Fakultas Sains dan Teknologi,

Universitas Islam Negeri Raden Fatah Palembang, Indonesia

\begin{abstract}
Abstrak: Sistem Informasi Inventaris Barang Pada Badan Pendapatan Daerah Provinsi Sumatera Selatan adalah sebuah sistem yang berbasis web dengan jaringan intranet dengan tujuan untuk mempermudah pengelolaan barang yang dimiliki oleh Badan Pendapatan Daerah Provinsi Sumatera Selatan dari mulai pengajuan permohonan hingga pengelolaan barang. Dengan menggunakan sistem ini diharapkan dapat membantu dan menghasilkan sebuah informasi untuk mencapai tujuan dari fungsi pengelolaan inventaris yang baik. Sistem yang dibuat berbasis intranet yang bertujuan untuk memudahkan proses pengelolaan inventarisasi yang hanya bisa dilakukan di lingkungan kerja Badan Pendapatan Daerah Provinsi Sumatera Selatan dari bagian pimpinan hingga ke lapisan unit kerja. Sistem Informasi Inventaris ini mencakup barang yang bergerak dan tidak bergerak yang meliputi peralatan dan perlengkapan kantor seperti peralatan elektronik, perlengkapan furniture, peralatan mesin, mobil dan sepeda motor. Proses yang ada pada sistem ini dimulai dari pengelolaan berkas permohonan pengadaan, perbaikan, mutasi, dan penghapusan. Serta laporan inventaris barang yang terkait dengan proses pengelolaan barang.
\end{abstract}

Kata Kunci: Sistem Informasi, Inventaris, Web

\begin{abstract}
Goods Inventory Information System at Local Revenue Agency of South Sumatera Province is a web-based system with intranet network with the aim to facilitate the management of goods owned by South Sumatera Provincial Revenue Board from start of application to management of goods. By using this system is expected to help and generate an information to achieve the goal of a good inventory management function. Intranet-based system that aims to facilitate the inventory management process that can only be done in the work environment of South Sumatera Provincial Revenue Board from the leadership to the work unit layer. This Inventory Information System includes movable and immovable goods covering office equipment and equipment such as electronic equipment, furniture supplies, machine tools, cars and motorcycles. The process that exists on this system starts from the management of the file of procurement, repair, mutation, and deletion requests. And inventory report of goods related to the process of goods management.
\end{abstract}

Keywords: Information System, Inventory, Web

\section{PENDAHULUAN}

Inventarisasi merupakan kegiatan untuk melakukan penghitungan, pencatatan, pendaftaran, dan penilaian terhadap semua barang milik negara berdasarkan Keputusan Menteri Keuangan No. Kep. 225/MK/V/4/1971. Dalam pengertian umum inventarisasi barang adalah kegiatan melaksanakan pengurusan, penyelenggaraan, pengaturan, pencatatan dan pendaftaran barang inventaris atau hak milik sebuah perusahaan atau instansi. 
Sistem informasi inventaris merupakan sebuah sistem yang dibuat dengan tujuan untuk membantu para penggunanya dalam menjalankan proses inventarisasi. Sistem informasi inventaris dapat menjaga agar persediaan barang yang dimiliki oleh sebuah perusahaan atau instansi selalu tercukupi dan dapat meminimalisir biaya untuk pengadaan barang yang terkadang kurang dibutuhkan oleh perusahaan atau instansi. Sistem informasi inventaris barang sangat diperlukan dalam sebuah perusahaan atau instansi karena berperan penting sebagai penunjang operasional kegiatan perusahaan. Salah satu bagian yang sangat penting dalam siklus pengelolaan adalah penatausahaan yang terdiri dari kegiatan pembukuan, inventarisasi dan pelaporan. Kegiatan inventarisasi lebih mengarah pada kegiatan atau tindakan untuk melakukan perhitungan, pengurusan, penyelenggaraan, pengaturan, pencatatan data dan pelaporan barang milik perusahaan, baik yang bergerak maupun yang tidak bergerak.

Badan Pendapatan Daerah merupakan sebuah instansi pemerintahan yang berperan sebagai badan pengelolaan pendapatan daerah yang mana berupa pengelolaan perpajakan. Sebagai salah satu instansi pemerintahan, Badan Pendapatan Daerah Provinsi Sumatera Selatan memiliki berbagai aset inventarisasi yang banyak seperti halnya barang-barang elektronik dan furniture. Dengan banyaknya aset atau barang yang dimiliki instansi tersebut tentunya dibutuhkan suatu sistem yang dapat mengelola barang-barang tersebut sebagai aset inventarisasi.

Dalam aktivitasnya saat ini pengelolaan inventaris barang di Badan Pendapatan Daerah Provinsi Sumatera Selatan masih dilakukan secara konvensional dan belum tersistematis yang mampu mengatur seluruh barang inventaris yang ada baik barang yang baru masuk, barang yang sedang tersedia, serta manajemen pengadaan, perbaikan, mutasi, dan penghapusan barang. Yang dapat mengakibatkan sering terjadinya kehilangan maupun kerusakan pada barang yang telah ada karena kurangnya perhatian atas pengelolaan barang yang telah disediakan.

Prosedur pengelolaan inventaris barang di Badan Pendapatan Daerah Provinsi Sumatera Selatan yaitu, barang hanya diberikan tanda pengenal atau kode inventaris pada saat pengadaan barang oleh pihak-pihak yang membutuhkan. Informasi barang yang keluar hanya dicatat dengan Ms. Excel saja. Terkadang ada juga barang yang disediakan tetapi tidak tercatat di Ms. Excel dan pengkodean barang yang dapat mengakibatkan kesalahan penomoran. Dengan banyaknya jumlah barang yang dimiliki serta pengelolaan data inventaris barang yang masih dilakukan secara konvensional dan belum tersistematis dalam hal ini hanya diberikan tanda pengenal berupa kode inventaris dan pencatatan dengan Ms. Excel, cara ini kurang efektif dalam pengelolaan data inventaris barang di badan pendapatan daerah provinsi sumatera selatan.

\section{METODOLOGI PENELITIAN}

\subsection{Tinjauan Pustaka}

\subsubsection{Sistem Informasi}

Sistem Infromasi adalah suatu organisasi yang mempertemukan kebutuhan pengolahan transaksi harian yang mendukung fungsi operasi organisasi yang bersifat manajerial dengan kegiatan strategi dari suatu organisasi untuk dapat menyediakan laporan-laporan yang diperlukan oleh pihak luar tertentu (Sutabri, 2012).

Sistem Informasi adalah suatu sistem di dalam suatu organisasi yang mempertemukan kebutuhan pengolahan transaksi harian, mendukung operasi, bersifat manajerial dan kegiatan strategi dari suatu organisasi dan menyediakan pihak luar tertentu dengan laporan-laporan yang diperlukan (Robert A. Leitch dan K. Roscoe Davis dalam (Jogiyanto, 2005). 


\subsubsection{Inventaris}

Menurut KBBI, yang dimaksud dengan inventaris adalah daftar yang memuat semua barang milik kantor (sekolah, perusahaan, kapal, dan sebagainya) yang dipakai dalam melaksanakan tugas (Anonim, 2017).

\subsubsection{PHP (Hypertext Prepocessor)}

PHP merupakan secara umum dikenal sebagai bahasa pmrograman script- script yang membuat dokumen HTML secara on the fly yang dieksekusi di sever web, dokumen HTML yang dihasilkan dari suatu aplikasi bukan dokumen HTML yang dibuat dengan menggunakan editor teks atau editor HTML. Dikenal juga sebagai bahasa pemrograman server side (Sidik, 2006).

PHP Hypertext Preprocessor atau disingkat dengan PHP adalah suatu bahasa scripting khususnya digunakan untuk web development. Karena sifatnya yang server side scripting, maka untuk menjalankan PHP harus menggunakan web server (Hidayatullah, 2014).

\subsubsection{Database}

Database (Multi file) adalah sekumpulan dari bermacam-macam file yang datanya saling berhubungan atau kumpulan dari data yang terintegrasi, diorganisasikan, disimpan dalam suatu cara yang memudahkan pengambilan kembali. Tujuan utama dari konsep database adalah meminimumkan pengulangan data dan mencapai independensi data. Independensi data adalah kemampuan untuk mengubah dalam struktur data tanpa membuat perubahan pada program yang memproses data (Suyanto, 2005).

\subsubsection{MySQL dan XAMPP}

MySQL adalah software atau program aplikasi database, yaitu software yang dapat dipakai untuk menyimpan data berupa informasi, teks dan juga angka (Nugroho, 2008).

$M y S Q L$ adalah salah satu aplikasi DBMS yang sudah sangat banyak digunakan oleh para pemrogram aplikasi web, kelebihan dari MySQL adalah gratis, handal, selalu di-Update dan banyak forum yang memfasilitasi para pengguna jika memiliki kendala (Hidayatullah, 2014).

$X A M P P$ adalah aplikasi web server bersifat instan (siap saji) yang dapat di gunakan baik di sistem operasi linux maupun di sistem operasi windows (Pratama, 2014).

\subsubsection{DFD (Data Flow Diagram) dan ERD (Entity Relationship Diagram)}

Data Flow Diagram (DFD) atau dalam Bahasa Indonesia menjadi Diagram Alir Data (DAD) adalah representasi grafik yang menggambarkan aliran informasi dan transformasi informasi yang diaplikasikan sebagai data yang mengalir dari masukan (input) dan keluaran (output) (Sukamto, R. A., \& Shalahuddin, M., 2013).

$E R D$ adalah gambar atau diagram yang menunjukkan informasi dibuat, disimpan, dan digunakan dalam sistem bisnis (Fatta, 2007).

\subsubsection{Prototype Model}

Metode Prototype adalah merupakan Metode pengembangan perangkat lunak yang memungkinkan adanya interaksi antara pengembang sistem dengan pengguna sistem, sehingga dapat mengatasi kesesuaian antara pengembang dan pengguna (Pressman, 2012).

\subsubsection{Pengujian (Testing)}

Pengujian merupakan proses eksekusi suatu program dengan tujuan menemukan kesalahan-kesalahan yang ada di dalamnya. Kasus pengujian yang baik adalah pengujian yang memiliki kemungkinan yang tinggi untuk menemukan kesalahan-kesalahan yang tidak ditemukan sebelumnya. Pengujian yang berhasil adalah pengujian yang mampu menyingkapkan kesalahan yang tidak ditemukan sebelumnya (Pressman, 2012). 


\subsection{Metode Pengumpulan Data}

Adapun teknik-teknik pengambilan data yang peneliti lakukan dalam penelitian adalah sebagai berikut:

1. Observasi (observation) merupakan teknik atau pendekatan untuk mendapatkan data primer dengan cara mengamati langsung objek datanya (Jogiyanto, Metodologi Penelitian Sistem Informasi, 2008). Observasi, atau pengamatan yang dilakukan di Badan Pendapatan Daerah Provinsi Sumatera Selatan yang berkaitan dengan sistem inventaris aset atau barang pada sistem yang sedang berjalan.

2. Wawancara (interview) adalah komunikasi dua arah untuk mendapatkan data dari responden. Wawancara dapat berupa wawancara personal (personal interview), wawancara intersep (intercept interview), dan wawancara telepon (telephone interview) (Jogiyanto, Metodologi Penelitian Sistem Informasi, 2008). Wawancara, pendekatan komunikasi untuk mencari dan mengumpulkan data dengan cara wawancara dengan responden yang dalam hal ini yaitu pegawai Badan Pendapatan Daerah Provinsi Sumatera Selatan.

3. Kepustakaan, Pengumpulan data yang dilakukan secara langsung dari sumber-sumber lain seperti buku, jurnal, dan hasil penelitian yang berkaitan dengan pokok permasalahan.

\subsection{Metode Pengembangan Sistem}

Metode pengembangan sistem yang digunakan pada penelitian ini adalah model Prototype. Metode pengembangan perangkat lunak yang memungkinkan adanya interaksi antara pengembang sistem dengan pengguna sistem, sehingga dapat mengatasi kesesuaian antara pengembang dan pengguna (Pressman, 2012).

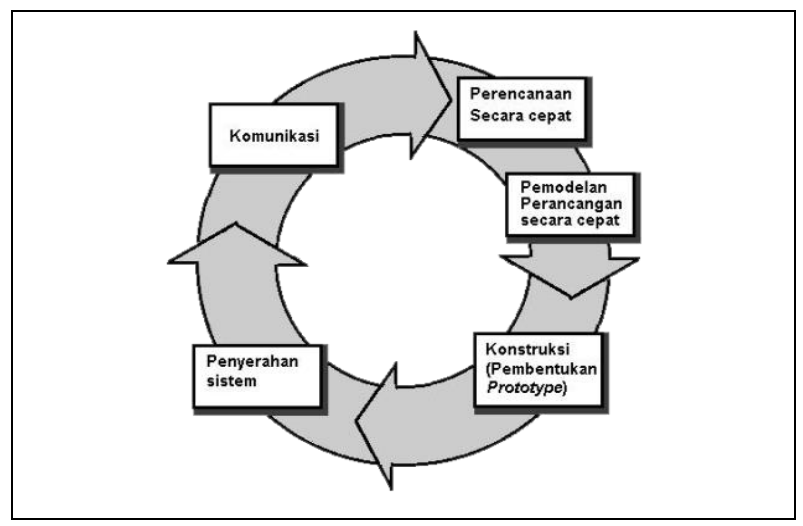

Gambar 1. Model Prototype

(Pressman, 2012)

Model Prototype merupakan salah satu model SDLC yang mempunyai ciri khas sebagai model proses evolusioner. Prototype sendiri bertujuan agar pengguna dapat memahami alur proses sistem dengan tampilan dan simulasi yang terlihat siap digunakan. Berikut ini penjelesan mengenai tahapan pada metode yang digunakan pada penelitian, yaitu:

1. Komunikasi.

2. Perencanaan.

3. Pemodelan.

4. Konstruksi.

5. Penyerahan.

Kecepatan dapat diterapkan pada proses perangkat lunak apapun, tetapi untuk dapat mencapainya sangatlah penting proses dirancang sedemikian rupa sehingga memungkinkan 
mengadaptasi dan mempermudah tugas, memungkinkan melakukan perencanaan sedemikian rupa sehingga muncul pemahaman atas perubahan dari pendekatan pengembangan cepat, memungkinkan mengeliminasi seluruh kecuali yang paling penting dan menjaga agar tetap ringkas, dan menekankan penghantaran yang menyampaikan secepatnya berdasarkan tipe dan lingkungan operasional yang dimiliki (Pressman, 2012).

\section{HASIL DAN PEMBAHASAN}

\subsection{Pemodelan}

\subsubsection{Data Flow Diagram}

Diagram konteks yang menampilkan arus data dari masing-masing entitas seperti Gambar 2 berikut ini:

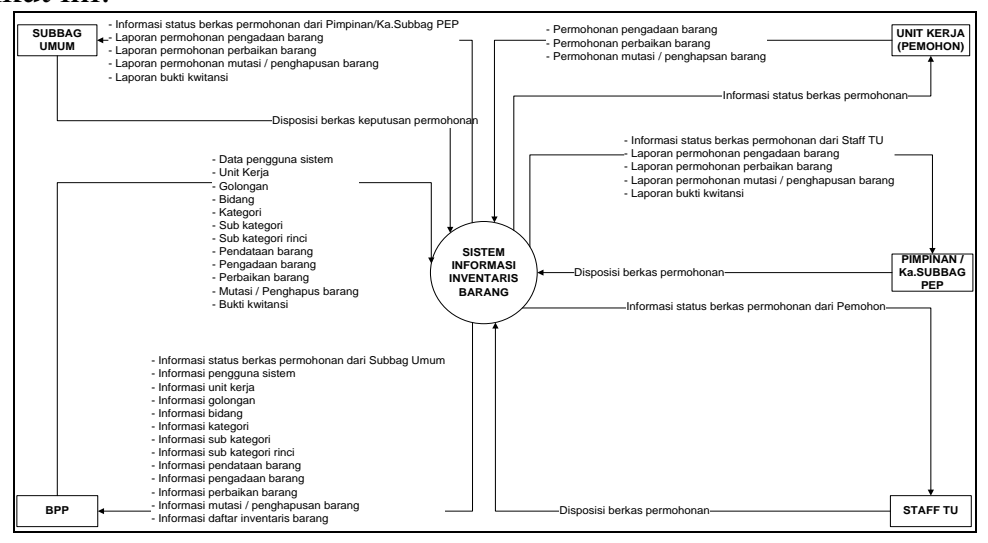

Gambar 2. Diagram Konteks Sistem Yang Dibangun

Entitas yang terdapat pada diagram konteks berjumlah 5 entitas dan setiap entitas memiliki arus data input dan output yang antara lain Unit Kerja (Pemohon), Staff TU, Pimpinan, Subbag. Umum, BPP(Administrator).

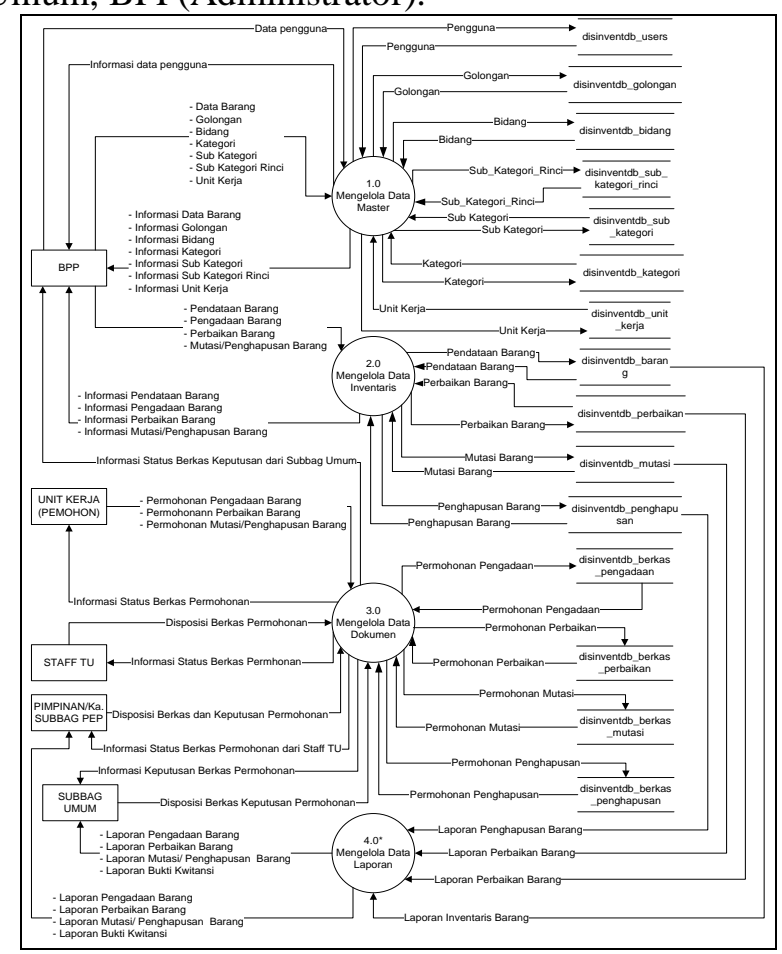

Gambar 3. Diagram Rinci Level 0 Sistem Yang Dibangun 


\subsubsection{Entity Relationship Diagram (ERD)}

Berikut ini adalah perancangan basis data menggunakan Entity Relationship Diagram (ERD) Sistem Informasi Inventaris Barang Pada Badan Pendapatan Daerah Provinsi Sumatera Selatan yang dapat dilihat pada Gambar 4:

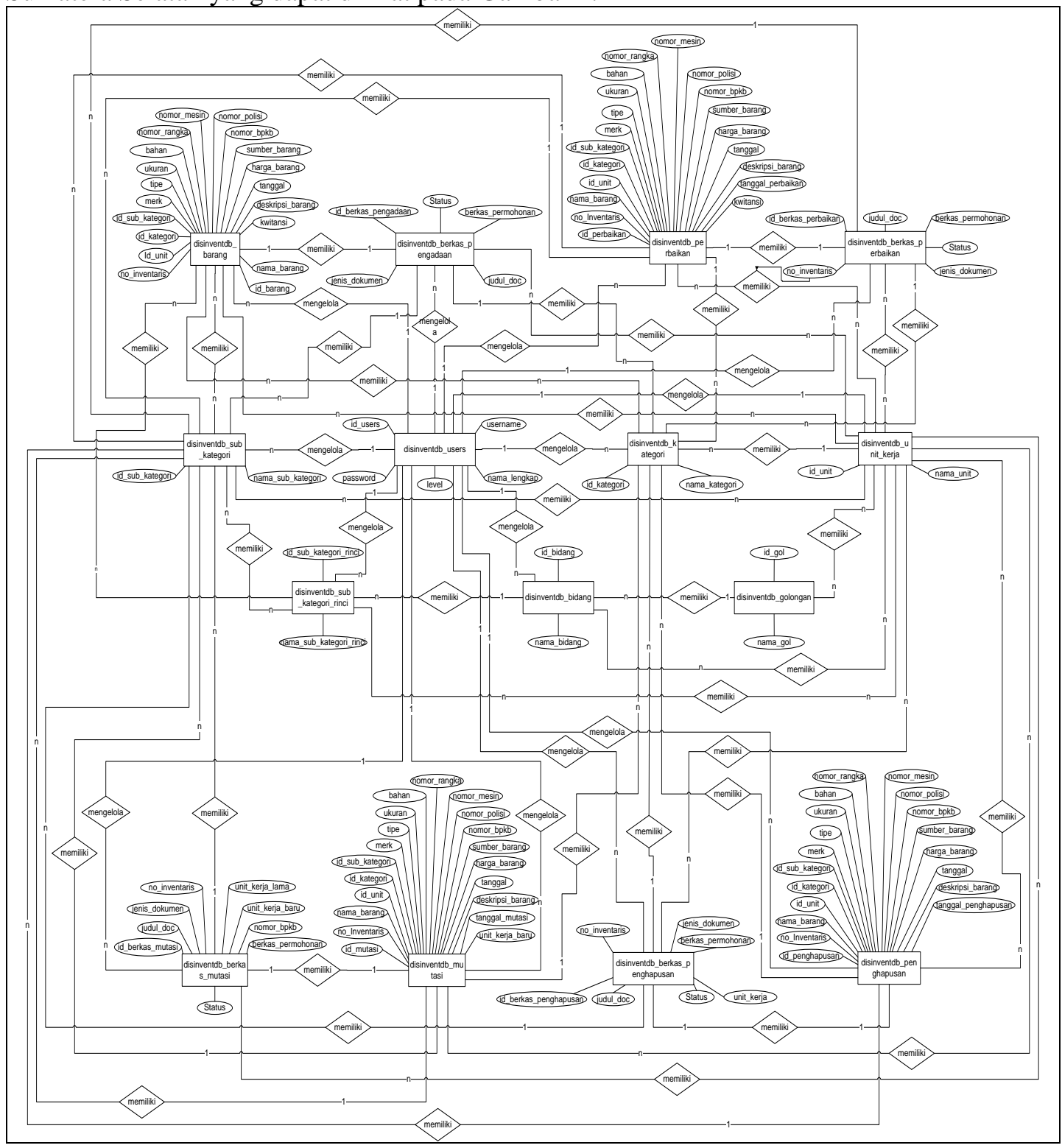

\section{Gambar 4. Perancangan Basis Data Sistem yang Dibangun}

\subsubsection{Interface Dashboard}

Pembahasan interface dashboard BPP(Administrator) adalah halaman yang berisi sebuah form yang berfungsi untuk melihat banyaknya data pengajuan berkas pengadaan, perbaikan, mutasi, dan penghapusan barang yang diajukan oleh unit kerja (pemohon), yang telah disetujui oleh pimpinan. Seperti yang dapat dilihat pada Gambar 5 dibawah ini: 


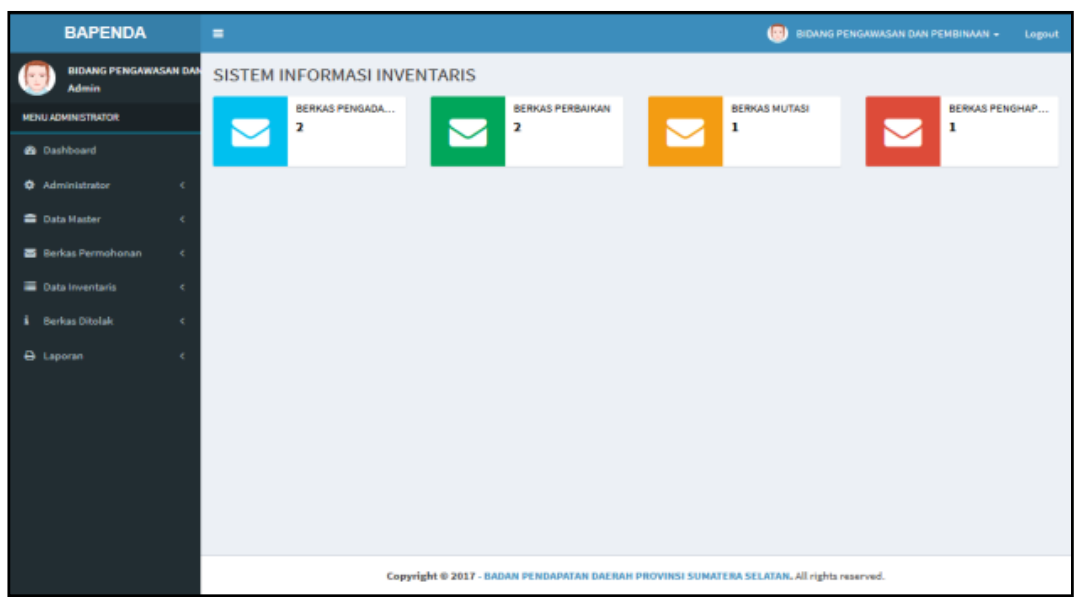

Gambar 5. Interface Dashboard

\subsubsection{Data Pengguna Sistem}

Data pengguna sistem berisi informasi-informasi data pengguna sistem yang berada di lingkungan kerja Badan Pendapatan Daerah Provinsi Sumatera Selatan. Data pengguna ini menampilkan data pengguna sistem yang dikelola oleh BPP sebagai Administrator Sistem. Untuk mempermudah mencari data pengguna telah disediakan form untuk pencarian data sehingga mempermudah untuk melihat data yang diinginkan. Berikut gambar pembahasan output data pengguna sistem dapat dilihat pada Gambar 6 dibawah ini:

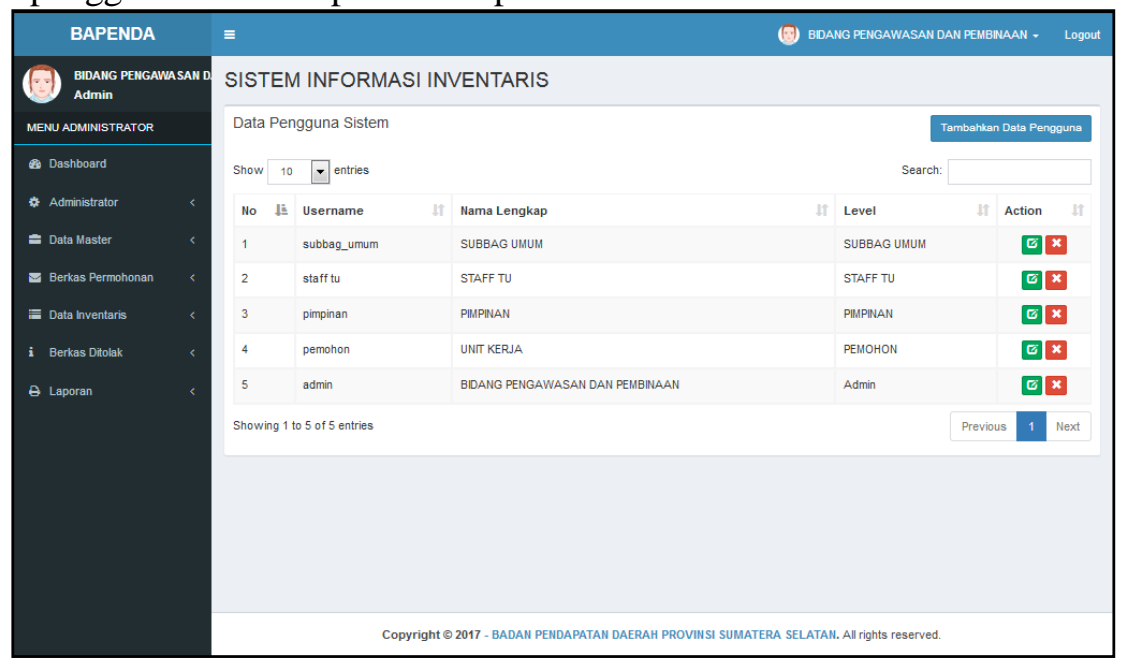

Gambar 6. Interface Data Pengguna Sistem

\subsubsection{Data Unit Kerja}

Data unit kerja berisi informasi data unit kerja yang ada di lingkungan kerja Badan Pendapatan Daerah Provinsi Sumatera Selatan. Halaman ini menampilkan data yang telah dikelola oleh BPP sebagai Administrator sistem. Telah disediakan form pencarian sehingga dapat mempermudah untuk melihat data yang diinginkan. Berikut gambar pembahasan output data unit kerja yang dapat dilihat pada gambar 7 dibawah ini: 


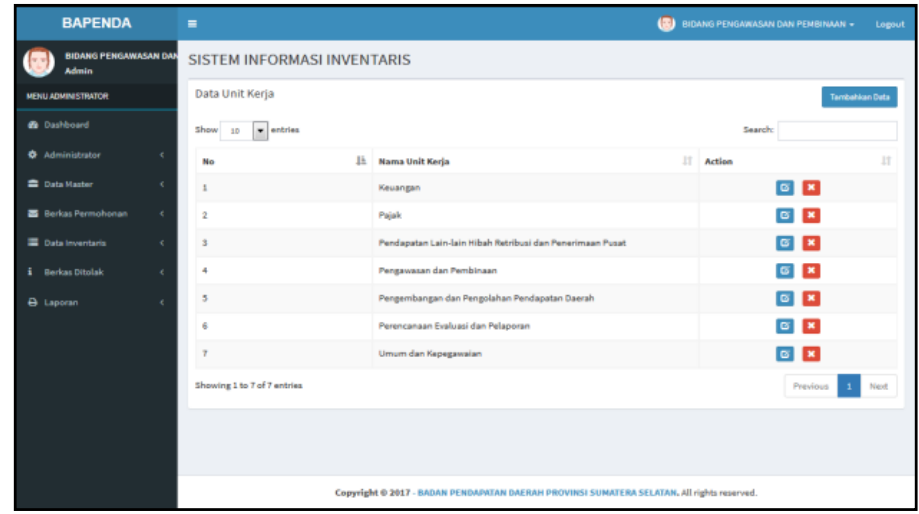

Gambar 7. Interface Data Unit Kerja

\subsubsection{Data Barang}

Data barang berisi informasi data barang yang ada di lingkungan kerja Badan Pendapatan Daerah Provinsi Sumatera Selatan. Data barang ini menampilkan data yang telah dikelola oleh BPP sebagai Administrator sistem. Telah disediakan form pencarian sehingga dapat mempermudah untuk melihat data yang diinginkan. Berikut gambar pembahasan output data barang yang dapat dilihat pada Gambar 8 dibawah ini:

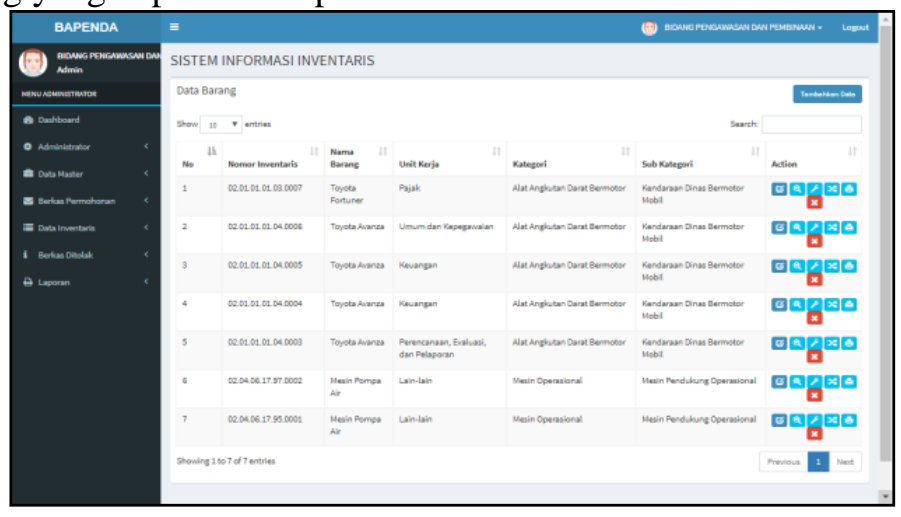

Gambar 8. Interface Data Barang

\subsubsection{Laporan Inventaris Barang}

Laporan Inventaris Barang berisi informasi laporan inventaris barang yang dimiliki Badan Pendapatan Daerah Provinsi Sumatera Selatan. Berikut gambar pembahasan output laporan inventaris barang yang dapat dilihat pada Gambar 9 dibawah ini:

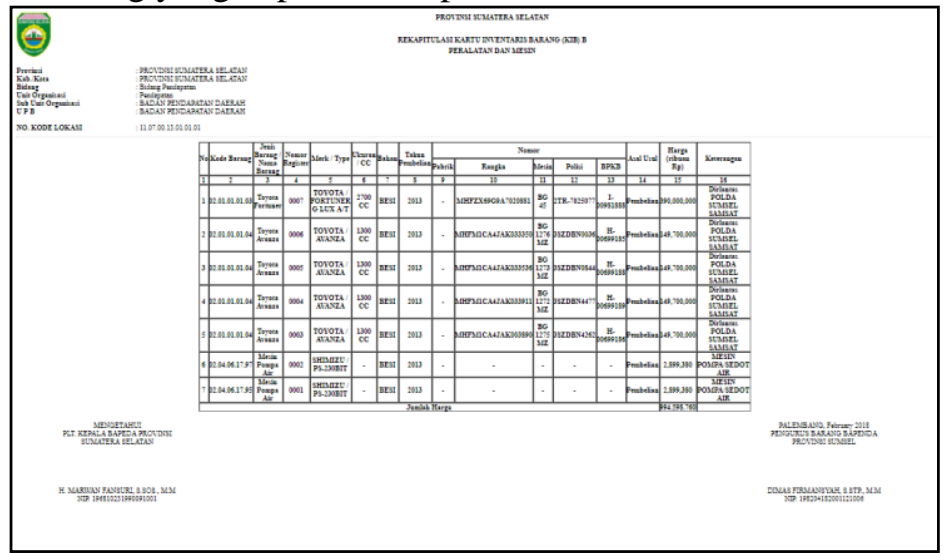

Gambar 9. Laporan Inventaris Barang

Volume 3, Nomor 2, Desember 2017 


\section{KESIMPULAN}

Dari hasil penelitian dan pengujian sistem informasi inventaris barang pada Badan Pendapatan Daerah Provinsi Sumatera Selatan, maka penulis dapat menarik kesimpulan sebagai berikut:

1. Sistem informasi inventaris barang yang sudah dibangun ini dapat membantu otimlisasi kinerja pegawai dalam proses pengelolaan barang yang ada pada badan pendapatan daerah provinsi sumatera selatan.

2. Sistem ini dapat melakukan pengelolaan permohonan pengadaan barang, perbaikan barang, mutasi barang, dan penghapusan barang.

3. Memiliki fitur filterisasi yang memungkinkan penggunanya untuk melakukan pengelompokkan pelaporan data inventaris barang berdasarkan unit kerja, kategori barang, sub kategori barang, periode awal, dan periode akhir pendataan barang.

\section{DAFTAR RUJUKAN}

Anonim. (2017, 05 02). Retrieved from https://www.kbbi.web.id/investaris

Fatta, H. A. (2007). Analisis \& Perancangan Sistem Informasi. Yogyakarta: Andi.

Hidayatullah, P. (2014). Pemrograman Web. Bandung: Informatika.

Jogiyanto. (2005). Analisis Dan Desain Sistem Informasi. Yogyakarta: Andi.

Jogiyanto. (2008). Metodologi Penelitian Sistem Informasi. Yogyakarta: Andi.

Nugroho, B. (2008). Latihan Membuat Aplikasi Web PHP dan MySQL Dengan

Dreamweaver MX. Yogyakarta: Gava Media.

Pratama, I. P. (2014). Sistem Informasi dan Implementasinya. Bandung: Informatika.

Pressman, R. (2012). Rekayasa Perangkat Lunak (Pendekatan Praktisi) Edisi 7. Yogyakarta:

Andi.

Sidik, B. (2006). Pemrograman Web Dengan PHP. Bandung: Informatika.

Sukamto, R. A., \& Shalahuddin, M. (2013). Rekayasa Perangkat Lunak Terstruktur dan Berorientasi Objek. Bandung: Informatika.

Sutabri, T. (2012). Konsep Sistem Informasi. Yogyakarta: Andi.

Suyanto, M. (2005). Pengantar Teknologi Informasi untuk Bisnis. Yogyakarta: Andi. 
126 | JUSIFO (Jurnal Sistem Informasi), p-ISSN: 2460-092X, e-ISSN: 2623-1662 